\title{
SELAYANG PANDANG TENTANG TEOLOGI FEMINIS DAN METODE BERTEOLOGINYA
}

\author{
Minggus M. Pranoto \\ Sekolah Tinggi Theologia Abdiel \\ minggusminarto@gmail.com
}

\begin{abstract}
The rise of women's movement and feminist theology show to us about the critical consciousness of women's experiences in the patriarchal society. They have fought against the patriarchal society supported by culture and religion. Many women have struggled for their self-respect, justice, and freedom. They have wanted to have an equal right and obligation with man either in church or in society. The aim of this paper is to describe the background of the rise offeminist theology and the richness of Feminist theological method.
\end{abstract}

Keywords: teologi feminis, perempuan, pengalama, gender, masyarakat patriarkat

\section{Pendahuluan}

Istilah feminisme, seperti halnya kapitalisme dan nasionalisme, adalah a modern word atau sebuah kata yang muncul sebagai produk zaman modern. Arti kata itu sendiri berbicara tentang suatu ideologi yang berisi sejumlah gagasan yang dipakai untuk memperjuangkan perubahan sosial. ${ }^{1}$ Sebutan feminisme menjadi kata kunci untuk mengekspresikan gelombang kedua dari gerakan perempuan yang muncul pada akhir tahun 1960-an. Jika gelombang pertama di akhir abad ke-19 dan di awal abad ke-20 isu-isu perjuangannya meliputi pembaruan posisi perempuan di masyarakat, emansipasi, kemandirian ekonomi, dan kerja. Gelombang kedua mencakup pokok-pokok persoalan seperti perjuangan untuk merombak budaya dan aturan dari masyarakat yang dikuasai oleh sistem patriakisme; usaha memunculkan kesadaran mengenai dampak-dampak berbahaya atau bencana dari pemikiran dualisme; dan keinginan mengikuti prinsip-prinsip perempuan daripada prinsip-prinsip laki-laki. ${ }^{2}$

Dari faktor eksternal, sumber-sumber yang menyumbang bagi gerakan perempuan pada gelombang kedua di Amerika Utara dan Eropa adalah seperti adanya dorongan dari

\footnotetext{
${ }^{1}$ Letty M. Russel, Church in the Round: Feminist Interpretation of the Church (Louisville, Kentucky: Westminter/John Knox Press, 1993), 23.

${ }^{2}$ Elisabeth Moltman-Wendel and Melanie A. May, "Feminism", dalam Dictionary the Ecumenical Movement, peny. Nicholas Lossky, Jose Miguez Bonino, John Pobee etc. , $2^{\text {nd }}$ edition (Geneva: WCC Publications, 2002), 471.
} 
Konsili Vatikan II agar para teolog Katolik merespon the signs of the times; inspirasi teologi politik dari Jurgen Moltmann, Johann Baptist Metz, James Cone; dan usaha para teolog-teolog pembebasan untuk "do theology from the underside of history." 3 Sedangkan secara internal, Rosemary Radford Ruether mengatakan bahwa faktor yang sangat penting di akhir tahun 1960-an adalah adanya kondisi sosial yang memunculkan kesadaran dalam diri perempuan, yang mengharuskan mereka untuk memiliki pendidikan dan agensi (agency) dalam lembaga-lembaga gereja. ${ }^{4}$ Gelombang-gelombang gerakan perempuan yang dipaparkan di atas memengaruhi munculnya Teologi feminis di Amerika Utara dan Eropa.

Pada tahun 1980-an muncullah Womanist theology sebagai kritik terhadap teolog feminis kulit putih di Amerika Utara karena mereka tidak berjuang bagi perempuan berwarna kulit lain, khususnya perempuan kulit hitam keturunan campuran AfrikaAmerika, baik yang tinggal di Amerika maupun yang tinggal tersebar di negara-negara lainnya. ${ }^{5}$ Sedangkan gerakan perempuan di Asia secara organisasi dan oikumene baru muncul di akhir tahun 1970-an dan teologi feminis Asia mulai berkembang kemudian di awal tahun 1980-an. ${ }^{6}$

Meski pemicu utama bagi teologi feminis di zaman modern adalah gerakan perempuan di Amerika Utara dan Eropa, namun ini tidak berarti bahwa kita boleh melupakan catatan sejarah — apa yang disebut Ruether sebagai proto and early feminist theological writings - tentang adanya warisan perjuangan perempuan di masa lalu yang dituangkan dalam pemikiran teologi mereka, misalnya dari para teolog mistik perempuan di abad pertengahan bernama Hildegard dari Bingen and Julian dari Norwich; dan dari abad keempat belas sampai ketujuh belas dengan tokoh-tokohnya seperti Christian de Pisan di Perancis, Marie Dentière di Jenewa, pemimpin perempuan Quaker Margaret Fell, tokoh perempuan Anglikan Mary Astell; sedangkan di abad ke-19 tokoh-tokoh perempuan

${ }^{3}$ Linda Hogan, "Feminist theology", dalam Enclopedia of Christianity, peny. John Bowden (Oxford: University Press, 2005),459.

${ }^{4}$ Rosemary Radford Ruether, "Feminist Theology", dalam The Routledge Companion to Modern Christian Thought, peny. Chad Meister and James Beilby (London \&New York: Routledge Taylor \& Francis Books, 2013), 583.

5 Lihat Evelyn L. Parker, "Womanist Theory," dalam The Routledge Companion to Modern Christian Thought, peny. Chad Meister and James Beilby (London \&New York: Routledge Taylor \& Francis Books, 2013).

${ }^{6}$ Lihat Kwok Pui Lan, "Feminism, Christian" dalam, A Dictionary of Asian Christianity, peny. Scott W. Sunquist (Grand Rapids, MI \&Cambridge, UK.: William B. Eerdmans, 2001), 286. Gerakan perempuan Asia ini dapat dilihat kiprahnya di the Women's desk of the Christian Conference of Asia dan the Women's Commission of the Ecumenical Association of Third World Theologians. Sedangkan teolog-teolog perempuan Asia seperti Marriane Katoppo, Mary John Mananzan, Virginia Pabella, Elizabeth Tapia, Cho Wa Soon, Chung Hyun Kyung, Lee Oo hung, Kwok Pui Lan, Hisako Kinukawa, Nantawan Boonprasat Lewis, Aruna Gnanadason, dan Stella Baltazar. 
yang menyuarakan hak-hak perempuan seperti Sarah Grimke, Lucretia Mott dan Elizabeth Cady Stanton dan yang lainnya. ${ }^{7}$

Munculnya gerakan perempuan dan teologi feminis menunjukkan adanya kesadaran kritis perempuan. Perempuan berjuang melawan masyarakat patriarkal yang disokong oleh budaya dan agama. Perempuan berjuang demi harga diri, keadilan, dan pembebasan mereka. Perempuan menghendaki partisipasi setara antara mereka dan lakilaki baik di gereja maupun di masyarakat. Selanjutnya tulisan ini akan fokus membahas mengenai seluk beluk teologi feminis dan tema-tema utama yang terkandung di dalamnya.

\section{Teologi dan Metode Feminisme}

Para teolog feminis menuduh bahwa Yudaisme dan kekristenan adalah sexist religions (agama-agama seksis), ${ }^{8}$ dengan konsep Allah sebagai laki-laki dan tradisi kepemimpinan laki-laki telah melegitimasi superioritas laki-laki di keluarga dan masyarakat. ${ }^{9}$ Agama seksis dipengaruhi oleh pandangan dualisme. ${ }^{10}$ Agama seksis juga mengekspresikan dirinya dalam patriarkatisme dan androisme baik melalui simbol-simbol budaya dan agama maupun dalam struktur sosial. ${ }^{11}$ Paradigma patriarkalisme dan androisme ditolak oleh para teolog feminis karena tidak memosisikan perempuan memiliki imago dei seutuhnya yang setara dengan laki-laki. ${ }^{12}$ Ruether menyebut seksisme sebagai

\footnotetext{
${ }^{7}$ Ruether, "Feminist Theology", 585. Lihat juga di Natalie K. Watson, Feminist Theology (Grand Rapids, MI dan Cambridge, UK.: William B. Eerdmans, 2003), 17-20 dan Hogan, "Feminist theology", 459.

${ }^{8}$ Sebuah agama seksis adalah agama, yang dalam terminologi modern, dipengaruhi oleh paham sexisme. Kata yang terakhir ini dijelaskan oleh Margaret Faley sebagai "belief that persons are superior to one another on the basis of their sex. It includes, however, attitudes, value system, and social patterns which express or support this belief." Lihat dalam "Sexisme", dalam New Catholic Encyclopedia (New York: McGraw Hill, 1978) 17:604.

${ }^{9}$ Lihat Carol P. Christ dan Judith Plaskow peny. "Introduction", dalam Women Spirit Rising: A Feminist Reader in Religion (San Fransisco: Harper Collin, 1998), 1.

${ }^{10}$ Ruether mengatakan bahwa pikiran dualisme ini terbentuk pada masa agama klasik (classical religion) kira-kira pada abad 6 sZB, dimulai dari Zoroasterisme, Platonisme, dan nabi-nabi Yahudi kemudian diperluas pada pembentukan kekristenan klasik, Talmud Judaisme, dan Islam. Dualisme membagi realitas dalam polarisasi yang berbeda bahkan bertentang satu dengan lainnya, misalnya seperti pemisahan antara sakral dan sekuler, individu dan komunitas, jiwa dan tubuh, materi dan spiritual, dunia sekarang dan "yang akan datang."Lihat Rosemary Radford Reuther, Liberation Theology: Human Hope Confronts Christian History and American Power (New York \& Paramus \& Toronto: Paulist Press, 1972), 5-6.

${ }^{11}$ Patriarkatisme, berasal dari kata patriarkat (bahasa Yunani patêr/patros yang artinya bapak dan archē artinya asal mula, kuasa untuk memerintah atau otoritas), yang artinya sebuah ideologi yang menekankan bentuk organisasi sosial dan dominasi kekuasaan di tangan laki-laki. Sedangkan androisme, berasal dari kata andros (bahasa Yunani anēr/andros artinya manusia laki-laki) yang artinya ideologi yang mengokohkan bahwa pola-pola pikiran dan tindakan yang kental dengan karakteristik kekuasaan laki-laki yang menjadi standar norma bagi semuanya. Lihat Elizabeth A. Johnson, She Who Is: The Mystery of God in Feminist Theological Discourse (New York: Crossroad, 1994), 23-24.

${ }^{12}$ Dalam sejarah teologi Kristen, banyak pemikir besar yang mengatakan bahwa perempuan tidak memiliki gambar Allah di dalam hidupnya atau kurang sempurna gambar Allah di dalam dirinya, misalnya seperti Augustinus yang menafsir I Korintus 11:7 dan hasilnya mengatakan bahwa perempuan tidak memiliki
} 
"the distortion of gender (as well as other differences between human groups) into structures of unjust domination and subordination-is central to the origin and transmission of this alienation, a fallen condition.",13

Usaha merekonstruksi paradigma yang baru tentang jender ${ }^{14}$ karena itu mutlak dibutuhkan dalam teologi feminis. Analisa dan kritik teologi feminis terhadap jender dalam masyarakat patriarkatsentris dan androsentris membantu juga dalam mengonsepkan interaksi di antara seksisme, rasisme, klasisme (classism), dan militer kolonialisme. ${ }^{15}$ Elisabeth Schüssler Fiorenza menegaskan bahwa “... feminism is not just concerned about gender but also about race, class, hetero normativity, and imperialism. It is concerned about kyriarchal power relations of domination.",16

Teologi feminis berusaha merekonstruksi semua simbol-simbol dasar dari keseluruhan sistem teologi Kristen seperti doktrin tentang Allah, manusia sebagai laki-laki dan perempuan, ciptaan, dosa, penebusan, pribadi dan karya Kristus, Gereja, dan pengharapan masa depan atau eskhatotolgi. Tema-tema misogynist serta laki-laki dalam tradisi teologi Kristen dilihat dalam perspektif inklusif jender dan egaliter. ${ }^{17}$ Pada sisi yang lain, Teologi feminis juga memunculkan tema-tema egaliterian di dalam kitab suci dan tradisi Kristen agar dapat membangun pemikiran baru dalam seluruh sistem teologi. ${ }^{18}$

Bagi teologi feminis, tidak semua simbol-simbol baik dari agama-agama maupun sosial budaya kontra terhadap perempuan. Masih banyak simbol-simbol berbicara mengenai nilai-nilai keharmonisan, keadilan, dan egaliterian. Teologi feminis terbuka

gambar Allah di dalam dirinya dan hanya laki-laki sajalah yang seutuhnya dan secara komplit memiliki gambar Allah. Thomas Aquinas mengatakan perempuan sebagai misbegotten male. Luther berpendapat karena perempuan jatuh dalam dosa maka ia dihukum dengan cara kehilangan kesetaraannya dengan lakilaki. Calvin menyebut perempuan sebagai ciptaan kedua (second in creation). Semua pendapat ini ujungujungnya ingin menyimpulkan bahwa perempuan itu inferior pada bagian tubuh, akal budi, moral, kehendak, dan kontrol dirinya dibandingkan laki-laki; dan oleh karena ia layak tersubordinasi di bawah laki-laki. Lihat Rosemary Radford Reuther, Women and Redemption: A Theological History (Minneapolis: Fortress Press, 2012), 59; Rosemary Radford Ruether, Sexism and God-Talk: Toward a Feminist Theology (Boston: Beacon Press, 1993), 96-97.

${ }^{13}$ Ruether, Sexisme and God-Talk, 37.

${ }^{14}$ Seks adalah istilah biologis dan gender adalah istilah sosial atau konstruksi sosial yang mengasosiasikan perempuan dengan realitas alam dan materi sebagai hal yang dioposisikan dari laki-laki dalam realitas budaya atau intelektual dan roh. Lihat Rachel Muers, "Feminism, Gender, and Theology," dalam The Modern Theologians, peny. David F. Ford dan Rachel Muers (Malden, USA: Blackwell , 2005), 435.

${ }^{15}$ Lihat Elisabeth Schüssler Fiorenza, "The Will to choose or to Reject: Continuing Our Critical Work", dalam Feminist Interpretation of The Bible, peny. Letty M. Russel (Philadelphia: The Westminster Press, 1985), 127

${ }^{16}$ Elizabet Schüssler Fiorenza, "Critical Feminist Biblical Studie: Remembering the Struggle, Envisioning the Future", dalam New Feminist Christianity: Many Voices, Many Views, peny. Mary E. Hunt and Diann L. Neu (Woodstock, Vermont: Sky Light Paths Publishing, 2010), 87.

${ }^{17}$ Ruether, "Feminist Theology",584.

18 Ibid. 
terhadap simbol-simbol dan juga nilai-nilai kebenaran lainnya meskipun semuanya itu berasal dari luar kitab suci Kristen. Kwok Pui Lan, seorang teolog feminis Asia, berpendapat bahwa sekarang ini orang-orang Kristen di Cina mempunyai kesadaran baru tentang nilai-nilai agung di dalam sastra-sastra mereka. Oleh karena itu, mereka mempelajari dan mengambil berbagai kebenaran dari kitab-kitab sastra kuno dan juga kitab-kitab suci lainnya seperti dari agama dan kepercayaan Konfusius, Taoisme, dan Buddhisme. ${ }^{19}$ Konstruksi teologi feminis ini adalah kritik terhadap apa yang yang disebut ortodoksi-penekanan pada otoritas kitab suci-dalam sistem teologi lama ${ }^{20}$; dan dengan demikian terbuka juga untuk dialog antar iman yang dapat mengokohkan perjuangan perempuan bersama di tengah-tengah konteks plural ini.

Apapun sumber-sumber yang diambil untuk mendukung teologi feminis yang jelas harus melewati prinsip-prinsip kritis, sebagaimana ditegaskan oleh Ruether, yaitu mesti mempromosikan kepenuhan perempuan sebagai manusia. Secara teologis, prinsip kritis itu menegaskan bahwa apa saja yang mengurangi atau menolak kepenuhan itu harus dianggap tidak merefleksikan "... the divine or an authentic relation to the divine, or to reflect the authentic nature things, or to be the message or work of an authentic redeemer or a community of redemption."21 Sebaliknya apapun yang mempromosikan kepenuhan tersebut adalah "... of the Holy, it does reflect true relation to the divine; it is the true nature of things, the authentic message of redemption and the mission of redemptive community. "22 Prinsip-prinsip kritis ini menjadikan teologi feminis mempunyai kriteria untuk membedakan simbolisasi dari dominasi dan kekuasaan yang menindas. Prinsipprinsip itu juga melakukan pencarian pesan-pesan kenabian untuk menegakkan keadilan dan mengafirmasi hubungan timbal balik antar manusia. ${ }^{23}$ Dengan demikian usaha yang mau dicapai adalah penebusan dari yang jahat dan perlawanan terhadap kelanggengan ketidakadilan. $^{24}$

${ }^{19}$ Lihat Kwok Pui Lan, Discovering the Bible in the Non-Biblical Word (New York, Maryknoll: Orbis Books, 1995), 12. Bandingkan dengan Ruether yang menaruh perhatian terhadap konsep Goddes spirituality dalam agama Timur kuno atau agama-agama di Mesopatmia yang mungkin dapat memberikan sumbangan terhadap pikiran feminisme. Lihat Ruether, Sexism and God-Talk, 38-40. Teolog feminis lainnya, Chung Hyun Kyung memakai gambaran tentang Kwan Yin (the East Asian goddes of compassion and wisdom) untuk membayangkan Roh Kudus dan gambar feminis Kristus (lihat dalam Muers, "Feminism, Gender, and Theology", 439-440).

${ }^{20}$ Lihat Karen King, "Canonization and Marginalization: Mary of Magdala," dalam Women' Sacred Scripture, Concilium 1998, no.3, peny. Kwok Pui Lan dan Elisabeth Schüssler Fiorenza (New York, Maryknoll: OrbisBook, 1998).

${ }^{21}$ Ruether, Sexism and God-Talk, 18-19.

22 Ibid.

${ }^{23}$ Ruether, "Feminist Theology", 585.

${ }^{24}$ Ibid. 
Keunikan teologi feminis terletak pada pengalaman perempuan. Pengalaman itu juga sebagai titik berangkat teolog feminis dalam berteologi. Menurut Carol P. Christ dan Judith Plaskow, para teolog feminis sering mengartikan pengalaman sebagai "the consciousness-raising group, which was developed to enable women to "get in touch with their own experience. "25 Pengalaman sebagai norma baru bagi perempuan dan melalui itu membawa mereka kepada "a critique of culture and to the tasks of transforming or recreating it." 26 Tambahan, "Naming women's experience thus becomes the model not only for personal liberation and growth, but for a feminist transformation of culture and religion. "27

Setidaknya ada dua kutub aliran dalam mengartikan pengalaman perempuan yakni pengalaman perempuan feminis (women's feminist experience) dan pengalaman perempuan tradisional (women's tradisional experience). ${ }^{28}$ Model pertama berbicara tentang pengalaman pembebasan itu sendiri melawan penindasan, budaya dan lembaga seksis, dan bergerak menuju kemerdekaan bagi perempuan. ${ }^{29}$ Nilai positif dari model ini adalah memampukan perempuan menggalang solidaritas dengan kelompok-kelompok tertindas lainnya. ${ }^{30}$

Model kedua berbicara soal pernikahan dan keibuan dalam diri perempuan atau disebut juga women's body experience. Isu-isu yang dibahas dalam model ini meliputi menstruasi, kehamilan, masa menyusui anak atau laktasi, berhentinya menstruasi atau menopause, dan mengasosiasikan perempuan tradisional dengan alam. Tambahan, apapun yang dipertimbangkan sebagai kefemininan atau feminine seperti intuisi, ekspresi perasaan, dimensi relasional personal perempuan juga menjadi topik-topik diskusi dalam model ini. ${ }^{31}$

${ }^{25}$ Christ dan Plaskow ed., "Introduction", 6.

${ }^{26}$ Ibid, 7.

27 Ibid.

${ }^{28}$ Christ dan Plaskow ed., "Introduction”, 8. Christ dan Palskow mengatakan bahwa kedua model itu sebenarnya bukan tidak serasi dan banyak perempuan mempunyai kategori dua pengalaman tersebut sekaligus. Namun demikian dua model itu mempunyai pengertian berbeda yang bernilai dan secara potensial transformatif bagi pengalaman perempuan. Dalam bahasanya Sallie McFague kedua model pengalaman ini menggambarkan tentang revolutionary feminist theology dan reformist feminist theology (Lihat Metaphorical Theology: Models of God in Religious Language (Philadelphia: Fortress Press, 1982),152-177.

${ }^{29}$ Christ dan Plaskow ed., "Introduction," 8. Model ini terwakili oleh tokoh-tokoh feminis seperti Ruether, Fiorenza, dan Sheila Collin yang percaya bahwa pengalaman pembebasan menyediakan pengertian spiritual mendalam dan menggunakan itu untuk memberi kritik terhadap tradisi. Tokoh lainnya Judith Plaskow dan Mary Daly menggunakan pengalaman feminis untuk mengkonstruksi pergertian baru tentang spiritualitas, yang berakar pada komunitas feminis.

${ }^{30}$ Christ dan Plaskow ed., "Introduction", 8.

${ }^{31}$ Ibid. Model ini terwakili oleh Carol Christ yang berbicara tentang keibuan; Penelope Wasbourn tentang menstruasi; Christ dan Starhawk mengenai simbolisme goddes dan Zsuzsanna Budapest yang mereklaim pengalaman perempuan dan bentuk tubuh-tubuh perempuan dari perspektif feminis. Perlu ditambahkan juga tokoh-tokoh feminis lainnya seperti Sallie McFague yang menulis tentang model-model 
Para teolog feminis dari model ini menempatkan women's body experience dan feminine dalam sebuah visi holistik feminis yang bertujuan membebaskan perempuan yang teralienasi selama ini dalam budaya dan teologi laki-laki. Model ini juga menegaskan, “... creating positive attitudes toward the female body is essential for women's liberation and that anything common to many women should be positively valued from a feminist perspective." 32 Teologi feminis model ini juga memberi nilai positif karena berbicara secara kreatif tentang teologi tubuh perempuan melalui menarik gambar-gambar, modelmodel, pemahaman-pemahaman mendalam (insights), dan konsep-konsep dari tubuh perempuan untuk menyediakan analogi-analogi tentang Allah atau hubungan Allah dengan dunia ini. ${ }^{33}$ Misalnya Allah digambarkan seperti ibu yang berelasi dengan anak-anaknya (umat-Nya) melalui tindakan-Nya mengandung dan melahirkan (Ul. 32:18; bnd. KPR 17:26,28) dan menyusui serta memberi makan (Yes. 49:15; Ruth 1:20-21) dan sebagainya.

Teologi tubuh juga menyediakan analogi-analogi hubungan antara Allah dengan dunia ini dan oleh para teolog ekofeminis analogi-analogi itu dipakai untuk menaruh perhatian pada isu-isu krisis ekologi dan bahaya nuklir. Mereka menganalogikan dunia ini sebagai tubuh Allah karena dunia dilahirkan dan diberi kehidupan oleh Allah sebagai ibu yang mencipta dan memelihara. Oleh karena itu segala macam perusakan terhadap alam adalah tindakan yang melukai dan menyakiti tubuh Allah. ${ }^{34}$

Metode teologi feminis titik berangkatnya adalah pengalaman perempuan dan itu dikaitkan dengan proses hermeneutik yang menuju kepada pemulihan (recovery) dan penginterpretasian kembali (reinterpretation) kitab suci Kristen dan tradisi. ${ }^{35}$ Ruether mengatakan bahwa proses itu meliputi tiga aspek yang saling berinteraksi: "(1) critique of misogyny and androcentrism in the biblical and theological tradition; (2) recovery of alternative, prophetic, egalitarian traditions; and (3) re-envisioning all the theological symbols in an egalitarian, justice-making way." 36 Teologi feminis mengkritik misogyny yang menegasikan perempuan yang dicatat di kitab suci Kristen. Misalnya seperti yang

Allah dalam bahasa agama dan Elizabeth A. Johnson yang menulis tentang misteri Allah dalam feminis diskursus teologi.

${ }^{32}$ Ibid, 9 .

${ }^{33}$ Lihat Sandra M. Schneider, Women and The Word (New York/ Marwah: Paulist Press,1986); Virginia Ramey Mollenkott, The Divine Feminine: The Biblical Imagery of God as Female (New York: Crossroad, 1987); Sallie McFague, Models of God: Theology for an Ecological, Nuclear Era (Philadelphia: Fortress Press, 1987) dan Metaphorical Theology: Models of God in Religious Language (Philadelphia: Fortress Press, 1982), dan juga Elizabeth A. Johnson, She Who Is: The Mystery of God in Feminist Theological Discourse (New York: Crossroad, 1994).

${ }^{34}$ Lihat Sallie McFague, Models of God:Theology for an Ecological, Nuclear Era (Philadelphia: Fortress Press, 1987).

${ }^{35}$ Ruether, "Feminist Theology", 586.

${ }^{36}$ Ibid. 
terdapat di I Timotius 2:13-14 yang merupakan penafsiran ulang dari Kejadian 1-3. Teksteks ini jelas mengekspresikan mysogyny yang berakibat menempatkan perempuan tersubordinasi terhadap laki-laki dan perempuan juga dituduh sebagai penyebab kejatuhan manusia ke dalam dosa. Ruether mengatakan, "By naming such a passage as "misogynist" one rejects it as authoritative for revealing the will of God and the true nature of God's will for humanity and creation. ,37

Ruether menegaskan bahwa apa yang telah dikatakan sebagai final dan definitif dalam tradisi teologi Kristen, misalnya seperti teologi tentang maksud Allah menciptakan laki-laki dan perempuan, kejatuhan dalam dosa, dan restorasi manusia berkaitan penebusan Allah, harus ditolak sebagai memiliki status pengajaran otoritatif karena teologi tersebut telah membentuk prasangka-prasangka negatif terhadap perempuan. ${ }^{38}$ Ini bukan berarti bahwa kitab suci Kristen tidak mempunyai otoritas lagi, namun bagian-bagian tulisan yang tidak sesuai dengan apa yang baik dan benar (Kej. 1:27) dan sesuai pesan-pesan Yesus yang revolusioner serta egaliter (Luk. 1:52) harus ditolak. ${ }^{39}$ Teologi feminis berdasar pada prinsip tentang Allah yang benar adalah Allah yang baik dan berkehendak baik. Implikasi prinsip ini adalah "Therefore any cultural and social constructions that mandate what is unloving and unjust in human relations are not of God and do not reflect the true nature or will of God. ",40

Untuk membedah kitab suci dengan dasar prinsip kritis sebagaimana dikatakan di atas maka teologi feminis menyadari bahwa keseluruhan kitab suci adalah androsentris. Ruether setuju pendapat Fiorenza dan menyimpulkan pendapat Fiorenza sebagai berikut: "the entire Bible is androcentric, not simply selected passages which are explicitly misogynist. The entire Bible was written by men (a dominant class and race of males) from a male point of view. It assumes that males are the normative human beings." Fiorenza, hermeneutics of suspicion harus digunakan dalam menafsir kitab suci agar dapat menemukan dan membuang lapisan-lapisan teologi androsentris yang menutupi arti orisinal sebenarnya dari teks-teks kitab suci. ${ }^{42}$ Berbeda dari Ruether yang jelas mengatakan bahwa ada texts of terror dari kitab suci Kristen karena di dalamnya terdapat tema-tema

\footnotetext{
${ }^{37}$ Ibid.

${ }^{38}$ Ruether, "Feminist Theology", 587.

${ }^{39}$ Ibid.

${ }^{40}$ Ibid.

${ }^{41}$ Ibid, 588.

${ }^{42}$ Elisabeth Schüssler Fiorenza, But She Said: Feminist Practices of Biblical Interpretation
} (Boston: Beacon Press, 1992), 23. 
misogynist, sebaliknya Fiorenza menegaskan bahwa teks-teks kitab suci itu tidak misogynist namun dalam lensa tafsir budaya laki-laki menjadi misogynist.

Selanjutnya yang penting bagi Fiorenza adalah perlunya mempunyai sebuah strategi feminis revisionis melalui "mendepatriarkatisasi” kitab suci. Fiorenza mengatakan, "A feminist revisionist strategy asserts that biblical texts themselves are not misogynist ... Consequently, the Bible must be "depatriarchalized" because, correctly understood, it actually fosters the liberation of women. ${ }^{, 43}$ Contoh teks-teks yang bisa dikerjakan dengan strategi revisionis ini misalnya di I Korintus 14 dan I Timotius 2 yaitu teks-teks yang melarang perempuan berbicara. Fiorenza setuju dengan Antoinette Brown seorang teolog feminis di tahun 1849, yang mengatakan ayat-ayat tersebut di atas tidak dapat dijadikan sebagai proof-texts untuk melarang perempuan berbicara di depan umum. Fiorenza mengutip penafsiran Brown atas teks-teks itu sebagai berikut: "They do not prohibit women's public teaching in general but only forbid a certain kind of faulty teaching. To make her point Antoinnete Brown resorted to two interlocking historical arguments: the depravity and low status of women in the surrounding culture of Judaism and GrecoRoman antiquity and the misbehavior of the church. "44

Pada tulisannya yang lain, Fiorenza menekankan bahwa pusat hermeneutik dari penafsiran biblikal feminisme adalah the women-church (ekklēsia gynaikōn), artinya "the movement of self-identified women and women-identified men in biblical religion. ${ }^{45}$ Bertolak dari memahami arti ekklēsia dalam terminologi Yunani sebagai pertemuan publik dari warganegara-warganegara merdeka yang berkumpul untuk menentukan kesejahteraan mereka dan anak-anak mereka; dan juga mempunyai arti sebagai perhimpunan, sinagoge, atau gereja perempuan (the church of women), kemudian Fiorenza menegaskan: "The ekklēsia of women is part of the wider women's movement in society and in religion that conceives itself not just a civil rights movement but as a women's liberation movement." Tujuannya gerakan feminis ini bukan sekadar mencapai kemanusiaan utuh perempuankarena arti kemanusiaan selama ini telah didefinisikan oleh laki-laki-tetapi afirmasi diri religius perempuan, kuasa, dan pembebasan dari semua alienasi patriarkat,marginalisasi,

\footnotetext{
${ }^{43}$ Fiorenza, But She Said, 23.

${ }^{44}$ Fiorenza, But She Said, 23. Lihat Antoinnete L. Brown, "Exegesis of I Corinthian XIV., 34, 35; and I Timothy II.,11.12”, dalam Oberlin Quarterly Review 5(1849): 372.

${ }^{45}$ Fiorenza, "The Will to Choose or to Reject", 126.

${ }^{46}$ Ibid.
} 
dan penindasan. ${ }^{47}$ Strategi ekklēsia gynaikōn dipakai oleh Fiorenza sebagai istilah yang menunjuk pada sikap oposisi dan politis kepada patriarkat. ${ }^{48}$

Akhirnya berkaitan dengan metode feminisme, Mary Daly memperingatkan para teolog feminis untuk berhati-hati dalam menggunakan metode teologi feminis mereka. Ia memperingatkan tentang bahaya apa yang ia sebut sebagai methodolatry sebagai sebuah kerangka opini tradisional dan tingkah laku yang tidak mau berubah yang menempatkan perempuan sebagai nondata and their questions nonquestions. ${ }^{49}$

\section{Bahasa Metafora Tentang Allah dan Isu-Isu Lainnya}

Bagi teologi feminis, bahasa mengenai Allah perlu direkonstruksi. Konsep Allah sebagai laki-laki adalah produk dari masyarakat patriarkat. Esther Kuntjara, setuju dengan Dale Spender, mengatakan "diskriminasi bahasa terhadap perempuan disebabkan karena bahasa adalah buatan laki-laki." ${ }^{50}$ Lebih lanjut ia menegaskan "bahasa telah dimanfaatkan oleh kelompok yang dominan (biasanya laki-laki) untuk menekan kaum perempuan. Ia mengatakan bahwa bahasa Inggris jelas-jelas dibuat dan ditentukan struktur kebahasaannya oleh kaum laki-laki. Bahasa Inggris menunjukkan ideologi patriarkat, di mana perempuan sering tidak dimunculkan."

Bahasa patriarkal memperkuat stereotip inferioritas perempuan dan superioritas laki-laki. Bahasa itu banyak memakai metafora laki-laki atau gambaran maskulin; akibatnya metafora lain yang beragam dan inklusif tentang Allah di kitab suci terabaikan. ${ }^{52}$ Banyak penolakan dari teolog-teolog feminis bermunculan terhadap bahasa patriarkat tentang Allah ini. Mary Daly menolak kalau Allah dipikirkan sebagai laki-laki, karena jika "God is male and male is God" $" 53$ maka konsep inilah yang membawa penindasan terhadap perempuan. Proposal metafora tentang Allah yang ia tawarkan ada beberapa seperti Allah sebagai Goddes The Verb, the Intransitive Verb, the Power of Be-ing yang intinya berbicara mengenai kekuatan yang memberdayakan perempuan; realitas ilahi imanen yang tidak kurang bermakna daripada realitas ilahi transenden; dan partisipasi kesatuan semua

\footnotetext{
${ }^{47}$ Ibid.

48 Ibid.

${ }^{49}$ Mary Daly, Beyond God the Father, Toward a Philosophy of Women's Liberation (Boston: beacon Press, 1973), 11-12.

${ }^{50}$ Esther Kuntjara, Jender, Bahasa, dan kekuasaan (Jakarta: Libri, 2012), 6.

${ }^{51}$ Ibid.

${ }^{52}$ Mary A. Kassian, The Feminist Gospel (Wheaton, IL: Crossway Books, 1992), 139-141.

${ }^{53}$ Daly, Beyond God the Father, 19.
} 
ciptaan dalam realita biophilic. ${ }^{54}$ Ruether menginjeksi konsep tentang God/ess sebagai source of being yang melampaui stereotip laki-laki dan perempuan ${ }^{55}$ atau "the foundation of our being and our new being embraces both the roots of the material substratum of our existence (matter) and also the endlessly new creative potential spirit.

Rebecca S. Chopp menggantikan metafora Allah sebagai Bapa menjadi Allah sebagai the Wordas the Perfectly Open Sign. Ia mengartikan Word dalam hubungannya dengan penciptaan, transformasi, hikmat, nyanyian, solidaritas dan perbedaan yang menurutnya dapat menjadi kemungkinan dan pertaruhan bagi diskursus-diskursus feminis. ${ }^{57}$ Ia mengatakan, "It is necessary to speak of this Word as fully as possible, for only by doing so can Word, women, and words weave together emancipatory transformation."58 Delores William lebih memilih menggunakan kata Spirit untuk menggantikan bahasa Allah yang menurutnya cenderung ke jender tertentu saja. ${ }^{59}$ Dalam pemilihan metafora untuk Trinitas, teolog-teolog feminis lebih suka menyebut "God as Creator, Redemeer, Sustainer” daripada kepada formula doktrin selama ini yang menunjuk kepada orientasi seksualitas tertentu. ${ }^{60}$

Kritik-kritik di atas ini relevan akibat penggunaan bahasa oleh patriarkat yang membawa konsekuensi kepada penyalagunaan kuasa laki-laki terhadap perempuan. Namun demikian perlu diberi catatan bahwa metafora-metafora di atas cenderung bernuansa abstrak karena tidak menunjuk atau menggambarkan Allah sebagai suatu pribadi yang dapat diajak berdialog dan berkomunikasi. Bukankah pengalaman agamaniah dalam konteks kekristenan merupakan suatu pengalaman yang tidak abstrak? Sebagaimana yang disebut sebagai Rudolf Otto sebagai pengalaman yang memiliki mysterium termendeum et fascinans. ${ }^{61}$ Tambahan, McFague mengkritik konsep Daly, dan kritik ini dapat dipakai untuk lainnya terutama yang berbicara tentang Goddes, bahwa "its embrace of

\footnotetext{
${ }^{54}$ Ibid. Lihat juga karya Daly berjudul Pure Lust: Elemental Feminist Philosophy (Boston: Beacon, 1984). Dikutip oleh Marjorie Hewit Suchocki, "God, Sexism, and Transformation,” dalam Reconstructing Christian Theology, peny. Rebecca S. Chopp dan Mark Lewis Taylor (Minneapolis: Fortress Press, 1994), 40-41. Ini terkait dengan biophilia yang artinya "a hypothetical human tendency to interact or be closely associated with other forms of life in nature" dari http://www.merriam webster.com/dictionary/biophilia diakses pada 6 April 2016.

${ }^{55}$ Ruether, Sexism and God-Talk, 70.

${ }^{56}$ Ibid, 71.

${ }^{57}$ Rebecca S. Chopp, The Power To Speak (New York: Crossroad, 1989), 30.

${ }^{58}$ Chopp, The Power To Speak, 30.

${ }^{59}$ Delores Williams, "Womanist Theology," dalam Women Spirit Rising: A Feminist Reader in Religion, peny. Judith Plaskow dan Carol P. Christ (San Fransisco: Harper Collin Publishers). Dikutip oleh Chopp dan Taylor peny., Reconstructing, 42-43.

${ }^{60}$ Hogan, "Feminist theology", 460.

${ }^{61}$ Rudolf Otto, The Idea of the Holy, terj. John W. Harvey (Oxford: University Press, 1958), $12-$ 
stereotypical feminine virtues, which becomes a new form of "biology destiny," and its lack of critical dimension in its elevation of women as savior of self and world." selanjutnya adalah "If the Goddes is women, every women, then the idolization of woman follows ..."63

Beberapa teolog lain yang masih mempertahankan metafora feminis untuk menggambarkan tentang Allah misalnya seperti Virginia Ramey Mollenkott yang menyebut Allah sebagai "a nursing mother, female pelican, mother bear, mother eagle, mother hen," dan sebagainya; ${ }^{64}$ dan Phyllis Trible yang menawarkan bahwa kita sebaiknya menggunakan metafora dalam bentuk bahasa, baik yang feminis seperti Allah adalah Ibu maupun yang maskulin untuk Allah. ${ }^{65}$ Perlu juga disebutkan di tulisan ini mengenai seorang teolog laki-laki yang nampaknya pro dengan teologi feminis, yaitu Jurgen Moltmann. Baginya, bahasa tentang Allah sebagai Bapa tidak perlu dihapus tetapi sebaiknya sebutan itu dipahami sebagai the motherly father karena Allah adalah the father of the 'first-born' Son. Ia adalah Bapa yang mengandung dan melahirkan putra-Nya yang sulung itu. "A father who both begets and gives birth to his son is no mere male father. He is a motherly father. He can no longer be defined as single-sexed and male, but become bisexual or transexual. He is the motherly father of his only-born Son, and the same time the fatherly Father of his only-born Son. "66 Memang kritik tetap dapat diberikan kepada Moltmann bahwa "the motherly father" itu tetaplah father sebagai metafora Allah dalam bahasa maskulin walau ada dimensi feminimnya juga.

Teolog-teolog di atas ini menampilkan metafora maternal sebagai penyeimbang metafora paternal tentang Allah. Metafora parental ini dikritik oleh McFague karena menurutnya metafora ini mengabaikan dimensi publik dan politis karena hanya fokus kepada dimensi individual saja di dalam realitas relasi kehidupan. Ia mengatakan "Parental models alone, however, whether maternal or paternal, are obviously insufficient ... they elevation and absoluting of divine compassion, guidance, and security for the individual, they neglect the public and political dimensions of that relationship ..." ${ }^{, 67}$. Alih-

\footnotetext{
${ }^{62}$ McFague, Methaporical Theology, 159.

${ }^{63}$ Ibid.

${ }^{64}$ Lihat Mollenkott, The Divine Feminine.

${ }^{65}$ Suchocki, "God, Sexism, and Transformation", 42.

${ }^{66}$ Jurgen Moltmann, “The Motherly Father: Is Trinitarian Patripassianism Replacing Theological Patriarchalism", dalam God as Father? Peny. John Baptist Metz, Edward Schillebeeckx, and M. Lefebure (Edinburgh: T\&T Clark; New York: Seabury Press, 1981), 51.

${ }^{67}$ Lihat McFague, Metaphorical Theology, 177-178. Di sini McFgue dipengaruhi oleh Yorick Spiegel, yang mengatakan "A theology (and this is something that political theology understands) located in the family situation, which nowadays is characterised by need-satisfaction and wish-fulfilment, must necessarily unilaterally favour the illusionary nature of belief to the disadvantage of its concern to banish
} 
alih mengikuti metafora parental ini, McFague mengusulkan God as friend yang menggambarkan tentang kebersamaan atau persekutuan dan kerja sama (Yes. 41:18; Mat. 11:19; Yoh. 15:13; Yos. 1:5; I Yoh.1:3, Yoh. 7:21; Hos. 2:23, I Kor. 3:9). ${ }^{68}$ Menurutnya metafora tersebut relevan - catatan bahwa McFague membicarakannya dalam konteks Barat-karena: pertama, banyak orang sekarang ini tidak mempunyai keinginan untuk menjadi orangtua (sebagai Bapak dan Ibu yang mempunyai anak-anak) dan oleh karena itu untuk memiliki pengalaman sebagai perempuan dan laki-laki tidak selalu dikaitkan dengan relasi parental. ${ }^{69}$ Tambahan, hubungan orangtua-anak tidak menjadi sentral lagi sekarang ini di konteks Barat. $^{70}$

Kedua, metafora parental tidak dapat mengekspresikan mengenai "mutuality, maturity, cooperation, responsibility, or reciprocity",71; tetapi hanya menekankan "the characteristics of compassion and acceptance as well as guidance and discipline." 72 Ketiga, era yang kita jalani sekarang ini "both the personal and political levels all kinds of people are working together for common causes, friendship expresses that ideal of relationship among people of all ages, both sexes, and whatever color or religion." 73 Menurut saya, konsep Allah sebagai sahabat dari McFague tidak cocok bagi kita yang tinggal di Asia yang sangat kuat menjaga relasi orangtua dan anak-anak. Jika konsep itu tidak dipertentangkan dengan dimensi parental mungkin dapat menjadi satu tambahan metafora untuk Allah yang dapat kita kembangkan lebih lanjut dalam konteks Asia.

Semua bahasa tentang Allah di atas menandakan bahwa semuanya adalah metafora. Kesalahan patriarkat adalah mengkultuskan metafora-metafora tertentu dan tidak terbuka bagi metafora-metafora lainnya. Para teolog feminis dapat terjatuh pada lubang yang sama jika mengabsolutkan bahasa metafora mereka. Padahal bahasa metafora itu tidak dapat sepenuhnya untuk menggambarkan tentang realitas yang disebutnya itu. Seinklusif apapun bahasa metafora tentang Allah tetap ada dalam keterbatasannya. Hal ini karena arti metafora adalah:

political repression and economic exploitation ... Only if the theological research succeeds in corporating family symbolism into the contemporary world-wide struggle for the humanization and self-assertion of the masses, is it possible for the religious symbolism of the family to become a truly guiding image ("God the Father in the Fatherless Society," dalam God as Father, 8-9.

\footnotetext{
${ }^{69}$ Ibid.

${ }^{70}$ Ibid.

${ }^{71}$ Ibid., 179.

${ }^{72}$ Ibid.

${ }^{73}$ Ibid.
}

${ }_{68}^{68}$ McFague, Metaphorical Theology, 178. 
... seeing one thing as something else, pretending "this" is "that" because we do not know how to think or talk about "this," so we use "that" as a way of saying something about it. Thinking metaphorically means spotting a thread of similarity between two dissimilar objects, events, or whatever, one of which is better known than the other, and using the better-known as a way of speaking about the lesser known. ${ }^{74}$

Pertanyaan kritis lainnya adalah apakah "persoalan pembahasaan tentang Allah ini menjadi persoalan penting dan utama juga bagi perempuan lainnya yang tinggal di luar wilayah yang berbahasa Inggris, misalnya seperti perempuan yang hidup di Asia?”

Selanjutnya, para teolog feminis menyadari bahwa pergantian metafora tentang bahasa Allah saja tidak akan mencukupi untuk mengadakan perubahan sosial, meskipun itu sangat penting karena berkaitan dengan pembentukan kesadaran kolektif yang baru tentang jati diri perempuan dan juga sebagai usaha untuk mengkonstruksi adanya realitas inklusif bagi perempuan. Timbul kesadaran-kesadaran baru di dalam diri para teolog feminis tentang agenda perjuangan secara sosial politik dan tidak sekadar mengkonstruksi jender pada level simbol-simbol baik yang ada di dalam agama maupun budaya. Berkaitan dengan perjuangan sosial politik ini, para teolog feminis kulit putih mendapat injeksi inspirasi dan kekuatan perjuangan tidak saja dari para teolog feminis kulit berwarna (hitam) di Amerika Utara, tetapi juga dari para teolog feminis yang berasal dari Dunia Ketiga baik dari Asia, Afrika dan Amerika Latin yang banyak menginspirasi tentang gambar-gambar Yesus termarginalisasi atau konsep hibrida (hybrid concept) tentang Yesus sebagai lambang-lambang perjuangan mereka melawan ketidakadilan. ${ }^{75}$ Kwok dengan tepat mengatakan sebagai berikut ini:

Still, I want to heed the advice I have repeatedly heard in ecumenical circles that inclusive language has not been a primary concern of women in the Third World. The struggle for gender justice, for those without safe water to drink and adequate food to put on the table, cannot be fought primarily at the cultural-symbolic level, without simuhultaneously attending to sociopolitical struggles. ${ }^{76}$

Dalam kaitannya dengan perjuangan-perjuangan sosial politik tersebut muncullah ide-ide kreatif para teolog feminis, untuk menghubungkan perjuangan mereka dengan isuisu poskolonialime. Memang ada beragam multiplikasi interpretasi tentang apa artinya

\footnotetext{
${ }^{74}$ Ibid, 14.

${ }^{75}$ Lihat Kwok Pui Lan, Postcolonial Imagination and Feminist Theology (Louisville \& Kentucky: Westminster John Knox Press, 2005), 168-185.

76 Ibid.
} 
poskolonialisme, namun intinya berbicara tentang perjuangan secara teori dan politik dari masyarakat yang mengalami transisi-dari sebelumnya sebagai masyarakat yang terjajah kemudian menjadi merdeka $;{ }^{77}$ dan oleh karena itu ada “ ... a desire, a determination, and a process of disengagement from the whole colonial syndrome, which takes many forms and guises. "78 Teori poskolonialisme juga mengkritisi wajah baru kolonialisme dan imperialisme seperti contohnya yang paling nyata melalui sistem ekonomi kapitalisme. Berkaitan dengan hal ini Kwok menekankan pentingnya mengartikan kembali atau memberi tanda secara baru lagi soal jender (resignifying gender) dan merombak kembali orientasi seksualitas (requeering sexuality) selama ini yang terjebak dalam konsep binerisme jender (gender binarism). ${ }^{79}$

Berkaitan dengan resignifying gender, teologi feminis menaruh perhatian kepada penindasan perempuan lintas budaya, yang terjadi baik secara lokal maupun global misalnya seperti “ ... the global teenage female workers in sexual, domestic, and service industries, Third World and poor migrant worker in richer countries, women of color in prisons, female refugees, and victims of war." 80 Sedangkan hubungannya dengan requeering sexuality, teologi feminis - terutama yang radikal dan liberal—setuju dengan pendapat para penganut teori queer bahwa seksualitas tidak dapat dibatasi pada normalitas binerisme dengan konsepnya yang baku tentang heteroseksualitas. Oleh karena itu adanya praktek homoseksualitas merupakan bukti bahwa pembakuan terhadap konsep normalitas binerisme dan heteroseksualitas adalah keliru.

Pembakuan tersebut bisa dikategorikan dalam dosa sexisme dalam perspektif teologi feminis. Pandangan teologi feminis (juga dari teori queer) tentang homoseksualitas menggoncangkan teologi konservatif tentang seksualitas dan konsep pernikahan heteroseksual. Sampai sekarang ini, konsep teologi feminis tersebut masih sulit diterima oleh gereja dan masyarakat. Ambil contoh misalnya di konteks masyarakat Indonesia yang religius dan patriarkat, usulan terhadap pernikahan sejenis dan usaha merombak pandangan tentang normalitas binerisme pasti akan ditentang dengan sangat kuat.

\footnotetext{
${ }^{77}$ http://plato.stanford.edu/entries/colonialism/ diakses pada tanggal 9 April 2016. Lihat juga beberapa pendapat tentang terminologi tentang poskolonialisme ini di Kwok, Postcolonial Imagination, 2.

${ }^{78}$ Anis Loomba, Colonialism/ Postcolonialism: The New Cultural Idiom (London: Routledge, 1999), 19. Dikutip dari Kwok, Postcolonial Imagination, 2.

${ }^{79}$ Kwok, Postcolonial Imagination, 128-144. Lihat juga Judith Butler, Gender Trouble: Feminism and Subversion of Identity (New York: Routledge, 1990).

${ }^{80}$ Chandra Talpade Mohanty, Feminism without Borders: Decolonizing Theory, Practicing Solidarity (Durham, N.C.: Duke University Press, 2003), 245-247. Dikutip oleh Kwok, Postcolonial Imagination, 136.
} 


\section{Kesimpulan}

Teologi feminis adalah teologi yang kreatif dan inovatif. Pengalaman perempuan diekplorasi sedemikian rupa melalui analisis dan refleksi teologis yang beragam dan mendalam serta dengan bantuan berbagai disiplin ilmu. Teologi ini tidak saja memunculkan banyak pandangan yang baru, namun juga memiliki kekuatan dalam praksisnya. Teologi ini menggoncangkan pandangan konservatif yang ada selama ini karena merekonstruksi simbol-simbol patriarkat dan memunculkan perjuangan perempuan secara sosial politik dalam konteks gereja dan masyarakat. Secara tepat Chopp mengatakan sebagai berikut: 'the 'achievements' of feminist theology, on its own terms, should be assessed not only through the texts produced and the ideas advanced but also through liberative changes in the lives of women and men. ",81

\section{Kepustakaan}

Brown, L. "Exegesis of I Corinthian XIV., 34, 35; and I Timothy II.,11.12", dalam Oberlin Quarterly Review 5 (1849): 372.

Butler, Judith. Gender Trouble: Feminism and Subversion of Identity. New York: Routledge, 1990.

Christ, Carol P dan Plaskow, Judith, peny. "Introduction", dalam Women Spirit Rising: A Feminist Reader in Religion. San Fransisco: Harper Collin, 1998.

Chopp, Rebecca S. The Power To Speak. New York: Crossroad, 1989.

"Feminist and Womanist Theologies", The Modern Theologians, peny. dalam D.F. Ford. Oxford, 1997.

Daly, Mary. Beyond God the Father, Toward a Philosophy of Women's Liberation. Boston: beacon Press, 1973.

Pure Lust: Elemental Feminist Philosophy. Boston: Beacon, 1984.

Fiorenza, Elisabeth Schüssler. "The Will to choose or to Reject: Continuing Our Critical Work", dalam Feminist Interpretation of The Bible, peny. Letty M. Russel. Philadelphia: The Westminster Press, 1985.

Boston: Beacon Press, 1992.

But She Said: Feminist Practices of Biblical Interpretation.

"Critical Feminist Biblical Studie: Remembering the Struggle, Envisioning the Future", dalam New Feminist Christianity: Many Voices, Many Views, peny. Mary E. Hunt and Diann L. Neu. Woodstock, Vermont: Sky Light Paths Publishing, 2010.

Hogan, Linda. "Feminist theology", in Enclopedia of Christianity, peny. John Bowden. Oxford: University Press, 2005.

\footnotetext{
${ }^{81}$ Rebecca S. Chopp, "Feminist and Womanist Theologies", The Modern Theologians, peny. dalam D.F. Ford (Oxford, 1997), 389-404. Dikutip dari Muers, "Feminism, Gender,and Theology", 447.
} 
Johnson, Elizabeth A. She Who Is: The Mystery of God in Feminist Theological Discourse. New York: Crossroad, 1994.

Kassian, Mary A. The Feminist Gospel. Wheaton, IL: Crossway Books, 1992.

King, Karen. "Canonization and Marginalization: Mary of Magdala," dalam Women' Sacred Scripture, Concilium 1998, no.3, peny. Kwok Pui Lan dan Elisabeth Schüssler Fiorenza. New York, Maryknoll: OrbisBook, 1998.

Kuntjara, Esther. Jender, Bahasa, dan kekuasaan. Jakarta: Libri, 2012.

Lan, Kwok Pui. Discovering the Bible in the Non-Biblical Word. New York, Maryknoll: Orbis Books, 1995.

. "Feminism, Christian" dalam, A Dictionary of Asian Christianity, peny. Scott W. Sunquist. Grand Rapids, MI \& Cambridge, UK.: William B. Eerdmans, 2000 .

Postcolonial Imagination and Feminist Theology. Louisville \& Kentucky: Westminster John Knox Press, 2005.

Loomba, Anis. Colonialism/ Postcolonialism: The New Cultural Idiom. London: Routledge, 1999.

McFague, Sallie. Metaphorical Theology: Models of God in Religious Language. Philadelphia: Fortress Press, 1982.

. Models of God: Theology for an Ecological, Nuclear Era. Philadelphia: Fortress Press, 1987.

Mohanty, Chandra Talpade. Feminism without Borders: Decolonizing Theory, Practicing Solidarity. Durham, N.C.: Duke University Press, 2003.

Mollenkott, Virginia Ramey. The Divine Feminine: The Biblical Imagery of God as Female. New York: Crossroad, 1987.

Moltmann, Jurgen. "The Motherly Father: Is Trinitarian Patripassianism Replacing Theological Patriarchalism", dalam God as Father? peny. John Baptist Metz, Edward Schillebeeckx, and M. Lefebure. Edinburgh: T\&T Clark; New York: Seabury Press, 1981.

Moltman-Wendel, Elisabeth and May, Melanie A. "Feminism", dalam Dictionary the Ecumenical Movement. peny. Nicholas Lossky, Jose Miguez Bonino, John Pobee etc., 2nd edition. Geneva: WCC Publications, 2002.

Muers, Rachel. "Feminism, Gender, and Theology," dalam The Modern Theologians, peny. David F. Ford dan Rachel Muers. Malden, USA: Blackwell, 2005.

Otto, Rudolf. The Idea of the Holy, terj. John W. Harvey. Oxford: University Press, 1958.

Parker, Lihat Evelyn L. "Womanist Theory," dalam The Routledge Companion to Modern Christian Thought, peny. Chad Meister and James Beilby. London \&New York: Routledge Taylor \& Francis Books, 2013.

Reuther, Rosemary Radford. Liberation Theology: Human Hope Confronts Christian History and American Power. New York \& Paramus \& Toronto: Paulist Press, 1972.

Beacon Press, 1993.

Sexism and God-Talk: Toward a Feminist Theology. Boston: 
Women and Redemption: A Theological History.

Minneapolis: Fortress Press, 2012.

Ruether, Rosemary Radford. "Feminist Theology", dalam The Routledge Companion to Modern Christian Thought, peny. Chad Meister and James Beilby. London \& New York: Routledge Taylor \& Francis Books, 2013.

Russel, Letty M. Church in the Round: Feminist Interpretation of the Church. Louisville, Kentucky: Westminter/ John Knox Press, 1993.

Schneider, Sandra M. Women and The Word. New York/ Marwah: Paulist Press, 1986.

Suchocki, Marjorie Hewit. "God, Sexism,and Transformation," dalam Reconstructing Christian Theology, peny. Rebecca S. Chopp dan Mark Lewis Taylor. Minneapolis: Fortress Press, 1994.

Watson, Natalie K. Feminist Theology. Grand Rapids, MI dan Cambridge, UK.: William B. Eerdmans, 2003.

Williams, Delores. "Womanist Theology," dalam Women Spirit Rising: A Feminist Reader in Religion, peny. Judith Plaskow dan Carol P. Christ. San Fransisco: Harper Collin Publishers. 